This is the peer reviewed, accepted manuscript of a chapter from the book MicroSyntactic Variation in North American English, published by Oxford University Press in July, 2014, available online:

https://doi.org/10.1093/acprof:oso/9780199367221.003.0007.

\title{
Iron Range English Reflexive Pronouns ${ }^{1}$
}

\begin{abstract}
This chapter offers new data from a Magnitude Estimation acceptability task that show that Iron Range English (IRE), which is spoken in the Arrowhead region of Minnesota, has long-distance reflexives. IRE reflexives (e.g., him-self) are long-distance reflexives, despite not, on the surface, sharing characteristics with long-distance reflexives in other languages: they are bi-morphemic, can corefer with subjects or objects, and exhibit both Blocking Effects and subject/verb agreement. However, IRE reflexives are neither indeterminate between anaphors and pronominals, nor are they are true logophors. Building on Katada (1991), this chapter suggests that IRE reflexives are operators that move successive-cyclically in LF to the edge of each clause, where they are in a local relationship with potential antecedents in higher clauses. Key words: long-distance reflexive, logophors, operators, Iron Range English
\end{abstract}

\footnotetext{
${ }^{1}$ Thanks to Hooi Ling Soh, who provided input on the analysis. Thanks also to Raffaella Zanutinni, Larry Horn, and Joan Maling for insightful comments and suggestions. Aspects of this paper were presented at the Linguistic Society of America's annual meeting in January 2011, and I am grateful to feedback from the audience at the conference. Thanks also to the IRE speakers and Minneapolis/St. Paul area English speakers who participated in the study. This research was funded by a Doctoral Dissertation Fellowship from the Graduate School of the University of Minnesota and a small grant from the Institute of Linguistics at the University of Minnesota. All errors and are mine. Lastly, I am a speaker of Iron Range English.
} 


\section{Introduction}

The cross-linguistic distribution of reflexive pronouns (e.g. himself) is characterized by substantial variation in locality constraints. In some languages, reflexive pronouns must be in the same local domain (roughly, the finite clause) as their antecedent (c.f. Chomsky's (1986) Binding Theory). This is illustrated below in English. Coreference is indicated with subscripts, and the finite clauses (here, the IP rather than the $\mathrm{CP}$ ) are indicated with brackets.

(1) a. Jim said that [Tomi likes himself $\mathrm{i}]$.

b. ${ }^{*} \operatorname{Jim}_{\mathrm{i}}$ said that [Tom likes himselfi $]$.

In other languages, such as Mandarin, Italian, and Icelandic, monomorphemic reflexive pronouns in certain environments can corefer with a nominal expression inside or outside their local domain. An example is given below in Mandarin. Here, ziji 'self' (a 'long-distance reflexive') can corefer with Lisi in the same simple finite clause as well as with Wangwu or Zhangsan, both of which are outside the simple clause containing the reflexive (Huang \& Tang 1989: 192).

(2) Zhangsan ${ }_{\mathrm{i}}$ shuo [Wangwu $\mathrm{Z}_{\mathrm{j}}$ zhidao [Lisi $\mathrm{W}_{\mathrm{k}}$ chang piping $\left.\mathrm{ziji}_{\mathrm{i} / \mathrm{j} / \mathrm{k}}\right]$.

Zhangsan said Wangwu know Lisi often criticize self

'Zhangsan said that Wangwu knows that Lisi often criticized self.'

Reflexive pronouns that are able to corefer with nominal expressions outside a local domain typically share a number of characteristics across languages: (i) they are monomorphemic (Pica 1987), (ii) they are subject oriented (Pica 1987), ${ }^{2}$ and (iii) in languages without subject/verb

\footnotetext{
${ }^{2}$ Cole and Wang (1996) suggest that at least in Mandarin Chinese subject orientation can be reduced to the notion of c-command since the reflexive can corefer with a non-subject nominal expression just when the nominal expression c-commands the reflexive at LF.
} 
agreement, they are "blocked" from coreferring with a nominal expression outside the minimal finite clause when there is an intervening nominal expression in subject position that does not match a lower subject for person (Huang 1984, Cole et al 1993). ${ }^{3}$

Since the late 1980s, the above characteristics have been taken to be the defining typological properties of long-distance reflexives. These properties have in turn been used to support analyses in which long-distance reflexives undergo LF head movement to a position where they are in a local relationship with nominal expressions in higher clauses (Battistella 1990, Cole et al. 1990, 1993, Cole and Sung 1994, Cole and Wang 1996, Cole and Hermon 1998, Hestvik 1992, Pica 1986, Sung 1990, inter alia). A head movement analysis makes the correct prediction that only mono-morphemic reflexive pronouns can be long-distance reflexives. In English, self is considered to be a head while bimorphemic reflexives (e.g., himself) are considered to be phrases. Hence, this analysis predicts that only mono-morphemic reflexives, which are heads, can be long-distance reflexives. This type of analysis also accounts for subject orientation since the reflexive raises in such a way that it is in a local relationship with the subject but not the object. Cole et al. (1993: 19) and Cole and Sung (1994) have posited Feature Percolation Principles to account for the existence of Blocking Effects only in languages without subject/verb agreement. The fact that Blocking Effects occur in some languages with long-distance reflexive pronouns (e.g., Mandarin), but not others (e.g., Italian) has led to analyses where binding and Blocking are considered to be separate processes (Cole 1990; Cole \& Sung 1994; Cole et al 2006; inter alia). If binding and Blocking involved the same process, we would not expect languages with long-distance reflexives to differ in terms of the existence of Blocking Effects.

\footnotetext{
${ }^{3}$ Note that the term "Blocking Effects" in this chapter, as well as in other work on the behavior of long-distance reflexives, is not used the same sense as in Aronoff(1976) and subsequent work on morphological processes.
} 
Bimorphemic counterexamples to the generalized behavior of long-distance reflexives have been shown to not be true counterexamples. Rather, they are shown to have either (i) an anaphoric and a pronominal distribution (in the sense of Chomsky (1986)) or (ii) an anaphoric and logophoric distribution (in the sense of Sells (1987)). Malay dirinya 'himself/herself' is an example of a reflexive pronoun that has both an anaphoric and a pronominal distribution (Cole and Hermon 2005). Evidence of a pronominal distribution comes from the lack of Blocking Effects in Malay, which also lacks subject/verb agreement. Its pronominal quality accounts for the lack of Blocking Effects, since pronouns can corefer with nominal expressions outside their minimal finite clause regardless of the person feature of intervening subjects. The Korean emphatic reflexive kucasin 'himself' and Japanese karezisin 'himself,' are examples of reflexive pronouns that have both an anaphoric and a logophoric distribution (Lee 2001). ${ }^{4}$ These reflexive pronouns can corefer with a nominal expression outside their simple finite clause in specific discourse/pragmatic environments. Logophoric pronouns must corefer with the one "whose speech, feelings, or general state of consciousness are reported" (Clements 1975: 141). These apparent counterexamples are not true counter-examples to the generalized distribution of longdistance reflexives because they are not true long-distance reflexives. ${ }^{5}$

In this paper, I offer new data from a Magnitude Estimation acceptability task that show that

\footnotetext{
${ }^{4}$ The relationship between long-distance reflexives and the notion of logophoricity is currently unknown. It has been suggested that long-distance reflexives undergo a conversion from an anaphor to a logophor in certain environments. See section 4.2.2 and Cole et al (2006) for more information on logophors.

${ }^{5}$ It is possible that some long-distance reflexives undergo a logophoric conversion from an anaphor to a pronominal and this is what allows them to corefer with a nominal expression outside the minimal clause, as is suggested for Mandarin (Huang \& Liu 2001).
} 
Iron Range English (IRE) reflexive pronouns, which have a similar form to reflexive pronouns in standard varieties of English (e.g., him-self), represent a true counterexample to the observed properties of long-distance reflexives. IRE reflexive pronouns are a true counterexample because they: (i) can corefer with nominal expressions outside the simple finite clause even though they are bimorphemic, (ii) can corefer with expressions in both subject and object position, and (iii) exhibit Blocking Effects despite also being marked for subject/verb agreement. IRE reflexive pronouns are true counterexamples to the above characteristics of long-distance reflexives because (i) they are not indeterminate between anaphors and pronominals and (ii) they are not truly logophoric in nature. IRE reflexive pronouns do not share the above characteristics with other long-distance reflexives, yet they behave similarly to long-distance reflexives in other ways. For example, their distribution lends further support to an analysis in which the reflexive undergoes covert movement to a position where it is in a local relationship with nominal expressions in higher clauses (e.g., island effects and Blocking Effects). The distribution of IRE reflexive pronouns also provides support for an analysis in which binding and Blocking are separate processes. This is because both subjects and objects can act as binders, but only subjects can act as Blockers.

The paper is organized as follows. In §2, I give an overview of Iron Range English and illustrate that it is a distinct dialect of English with a unique history. In $\S 3$, I provide an overview of how IRE judgments were collected for this study. In $\S 4$ I report on the results. IRE reflexive pronouns can corefer with nominal expressions outside their simple finite clause despite being bimorphemic. Interestingly, IRE reflexives do not have a truly pronominal distribution nor do they have a truly logophoric distribution. This finding suggests that IRE reflexive pronouns are true long-distance reflexives. It also suggests that a syntactic analysis is appropriate to account for their distribution rather than a (partially) discourse or semantic analysis as would be appropriate for 
logophoric expressions. In $\S 5$, I present a phase-based analysis to account for the behavior of IRE reflexive pronouns. This analysis suggests that IRE reflexive pronouns have an operator-like quality that allows them to move to a location where they are in a local relationship with a nominal expression in a higher clause. I also propose separate binding and Blocking processes since different sets of nominal expressions are involved in Blocking and binding. $\S 6$ concludes the paper.

\section{Iron Range English}

Iron Range English is a unique dialect of English spoken on the Mesabi Iron Range, which is located in the Arrowhead region of northern Minnesota between Grand Rapids and Babbitt.

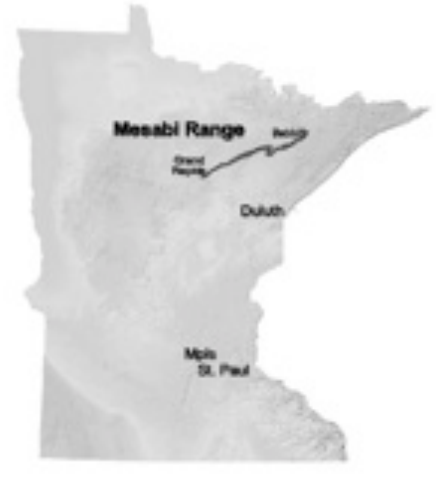

Figure 1: Map of Iron Range in Minnesota (provided by Tim Pastika, MN DNR lands and minerals, 1/2009)

Its uniqueness is probably due to a specialized immigration pattern not shared by the rest of the state of Minnesota. Before the discovery of iron ore in the 1880's, the Iron Range was largely uninhabited by immigrant Europeans: dense forests and rocky soil were both deterrents for wouldbe settlers who wanted to farm. During a small-scale gold rush in what is now the Vermilion Range, high-grade iron ore was found rather than gold. The ore (hematite) was so rich and so easy to mine that demands for laborers shot up after the first mine was built in Mountain Iron, MN in 1890 (De Kruif 1929, Geology 1887, Underwood 1981). Because of the mines' need for laborers, 
the population of the Iron Range increased from almost no people of European descent in the 1880's to over 70,000 by 1920 (Underwood 1981). The origins of early Iron Rangers were mostly: Cornish, English, French-Canadian, Swedish, Slovenian, Croatian, Polish, Italian, Bohemian, and Lithuanian (among others) (Sirjamaki 1965). Sirjamaki also suggests that while some inhabitants of the area immigrated to the Iron Range, some settlers may have come from other mining communities around the Great Lakes (such as Iron Mountain in the Upper Peninsula of Michigan). Sirjamaki states that by the mid 1930's, as many as one third of Iron Rangers had intermarried; therefore, he concludes that "[t]he range is actually a melting pot" (Sirjamaki 1965: 127).

Little research has been done on Iron Range English (c.f. Allen 1976, Underwood 1981, Linn 1988, Bauer 2005). Linn (1988) reports on a number of non-standard features of Iron Range English such as: (i) a unique lexicon (e.g., location means a housing area originally constructed by the mining companies), (ii) absence of copulas (e.g., he late means "he is late"), and (iii) nonstandard word order (e.g., you play with five cards just which means "you play with just five cards"). None of the above work examined the behavior of reflexive pronouns.

\section{Methods}

In order to document the distribution of IRE reflexives, I gathered judgments of sentences with reflexives from 31 speakers of Iron Range English (12 males, 19 females; Ages ranged from 22-77; $M=46.26, S D=15.66)$ and 12 speakers of standard Minnesota English from the Minneapolis/St. Paul (MSP) area (Ages ranged from 23-56; $M=36.5, S D=9.66$ ). Each stimulus began with a short situation that set up a potential long-distance interpretation of the reflexive.

Next, there was a target sentence that indicated intended coreference with capital letters. For example, in the sentence JOHN said that Matt believes in HIMSELF, himself was meant to corefer with John. Below the target sentence was an audio player. IRE speaking participants listened to an 
IRE speaker say the target sentence, and MSP speakers listened to a standard speaker say the sentence. Lastly, there was an open field for the naturalness rating. Words in capital letters were not interpreted as having contrastive focus, and they were produced without contrastive focus in the audio recordings. Below is an example of a stimulus:

\section{(3) Example Stimulus}

Situation: Matt may or may not believe in John, but John seems to think that Matt is confident in John's abilities. To describe this situation, could you say:

Target: JOHN said that Matt believes in HIMSELF.

Click here to listen to audio.

How natural does this sentence sound?

Rating:

Naturalness ratings were calculated using Magnitude Estimation (Bard et al 1996). Magnitude Estimation allows participants to create their own flexible scales of acceptability, thus allowing for higher resolution results than are produced with traditional acceptability surveys. Participants rated sentences against a previous modulus sentence. If the stimulus sentence was judged to be twice as natural as the modulus sentence, a rating twice as high as that given to the modulus was given to the stimulus. Magnitude Estimation was chosen because it offers the following advantages over paper and pencil surveys with pre-set acceptability scales: (i) it allows for potentially more levels of grammaticality to emerge from the data than a pre-set scale allows for, and (ii) it gives an informant the ability to more accurately report acceptability judgments of the data. For example, if a person rates a sentence that seems "pretty natural" with the highest number of a pre-determined scale, and then she encounters another sentence that is more natural, she has no means by which to show (i) that this second sentence is even more acceptable than the 
first and (ii) how much more acceptable this second sentence is than the first when she is using a pre-set scale.

In order to normalize the raw ME ratings across subjects, the following steps were taken based on the standard procedure outlined in Baylis (2007) and Engen (1971):

1. For each subject, calculate the logarithm of each response

2. For each subject, calculate the mean value of each of their (log-converted) responses

3. Calculate the grand mean of step 2

4. Subtract the grand mean of step 3 from the subject means of step 2

5. Add the values in step 2 to the values in step 4

6. Calculate the antilog of the values in step 5

\section{Results}

\subsection{General results}

Female IRE speakers 35 and older $(N=13 ; M=54.3 ; S D=14.39)$ rated sentences with longdistance reflexives (as in (4)) as significantly more natural than speakers from the Minneapolis/St. Paul area did $(t(23)=2.56, \mathrm{p}=.02){ }^{6}$

(4) a. $\mathrm{John}_{\mathrm{i}}$ thinks that [Matt believes in himself $\mathrm{i}_{\mathrm{i}}$.

b. John ${ }_{\mathrm{i}}$ thinks that [she believes in himself $\mathrm{i}_{\mathrm{i}}$.

\footnotetext{
${ }^{6}$ Some men (young and old) and some younger women could also use long-distance reflexives; however, their use of long-distance reflexives was not as consistent as women 35 years and older. Notably, only women 35 years and older said that they enjoy living on the Iron Range because they like the people who choose to live there. Men said they enjoy living on the Iron Range because it is close to hunting and fishing. None of the young women in the study said that they enjoy living on the Iron Range.
} 
Given that long-distance reflexives have been said to always be mono-morphemic, it is surprising that IRE himself, which is clearly bimorphemic, can corefer with a nominal expression outside its simple finite clause. ${ }^{7}$

Also, IRE reflexive pronouns can corefer with a nominal expression outside the simple clause not only in subject, but also in object position, as illustrated in (5):

(5) a. [Hillary told Jill $_{\mathrm{j}}$ that [Mary $\mathrm{k}_{\mathrm{k}}$ believes in herself $\left.\mathrm{f}_{\mathrm{j} / \mathrm{k}}\right]$ ].

b. [Hillary $\mathrm{i}_{\mathrm{i}}$ told $\mathrm{Jill}_{\mathrm{j}}$ that $\left[\right.$ Tom $_{\mathrm{k}}$ believes in herself $\left.\mathrm{f}_{\mathrm{i} / \mathrm{j}}\right]$.

Again, given that long-distance reflexives have been said to always corefer with nominal expressions in subject position, it is surprising that herself can corefer with a nominal expression outside the simple finite clause in object position. However, if we assume that in (4) both Hillary in subject position and Jill in object position c-command the reflexive, then this distribution can be seen as resembling that of long-distance reflexives in Mandarin Chinese: Cole and Wang (1996) have argued that in Mandarin subject orientation can be reduced to a c-command relationship between the reflexive and the antecedent.

IRE reflexives exhibit Blocking Effects: a reflexive pronoun cannot corefer with a nominal expression in the matrix clause when there is an intervening nominal expression in subject position that does not match the reflexive pronoun for person. Sentences with an intervening subject that does not match the reflexive pronoun for person were rated significantly less natural than sentences

\footnotetext{
${ }^{7}$ This situation may not be surprising, however, if IRE reflexives behave like logophoric expressions since logophoric expressions may be bimorphemic and locally free in specific discourse/pragmatic environments (ZribiHertz 1989, Baker 1995 inter alia). However, as illustrated later in the chapter, IRE reflexive do not have a fully logophoric distribution.
} 
in which all the nominal expressions in subject position match the reflexive pronoun for person $(t(12)=3.67, \mathrm{p}=.003)$. This is illustrated in (6).

(6) a. Hillaryi said that [she believes in herself $\left.f_{i}\right]$.

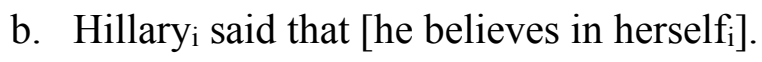

c. *Hillaryi said that [I believe in herselfi $]$.

d. *Hillaryi said that [you believe in herselfi].

In (6c) herself cannot corefer with Hillary because of the intervening first person pronoun subject; in (6d) herself cannot corefer with Hillary because of the intervening second person pronoun.

Interestingly, sentences where the intervening subject did not match the reflexive for number were rated similarly to sentences where all subjects agreed for person, number, and gender with the reflexive $(t(12)=1, \mathrm{p}=.341)$.

(7) a. John $n_{i}$ said that [they believe in himselfi].

b. John ${ }_{i}$ said that [they know that $\left[\right.$ Tom $_{j}$ believes in himself $\left.f_{i j}\right]$.

Also, sentences where the intervening subject did not match the reflexive for gender were rated similarly to sentences where all subjects agreed for person, number, and gender with the reflexive $(t(12)=1.1, \mathrm{p}=.12)$

(8) a. Johni said that [she believes in himselfi].

b. John $n_{i}$ said that [she knows that $\left[\mathrm{Tom}_{\mathrm{j}}\right.$ believes in himself $\left.\mathrm{f}_{\mathrm{i} j}\right]$.

Thus, only intervening subjects that do not match the reflexive for person trigger Blocking Effects. Subjects that did not match the reflexive for number or gender did not trigger Blocking Effects.

Only subjects trigger Blocking Effects. Sentences with objects that did not match the reflexive for person were rated similarly to sentences where the object matched the reflexive for person $(t(12)=1.71, \mathrm{p}=.11)$. 
(9) a. Hillary ${ }_{i}$ told me that $\left[\mathrm{Jill}_{\mathrm{j}}\right.$ believes in herself $\left.\mathrm{f}_{\mathrm{i} / \mathrm{j}}\right]$.

b. Hillary $\mathrm{i}_{\mathrm{i}}$ told me that [Tom believes in herself $\mathrm{f}_{\mathrm{i}}$.

Likewise, sentences with possessors that did not match the reflexive for person were rated similarly to sentences with possessors that matched the reflexive for person $(t(11)=1.04, \mathrm{p}=.32) .^{8}$

a. He thinks that [my behavior harmed himself $\mathrm{f}_{\mathrm{i}}$.

b. He $\mathrm{He}_{\mathrm{i}}$ thinks that [her behavior harmed himself $\mathrm{i}_{\mathrm{i}}$.

The literature has suggested that Blocking Effects occur only in languages with long-distance reflexives that lack subject/verb agreement. Given this, it is unexpected that IRE exhibits Blocking Effects, because it also exhibits subject/verb agreement, as illustrated in (11):

a. I like/*likes coffee.

b. You like/*likes coffee.

c. He *like/likes coffee.

Lastly, IRE reflexive pronouns that occur within islands (such as complex NPs, relative clauses, and interrogative clauses) cannot corefer with a nominal expression in the matrix clause, as illustrated below (where islands are indicated with brackets):

(12) a. John $n_{\mathrm{i}}$ made [the claim that Bill $l_{\mathrm{j}}$ likes himself $\left.*_{\mathrm{i} / \mathrm{j}}\right]$.

b. Bill $l_{\mathrm{i}}$ said that Paul $\mathrm{j}_{\mathrm{j}}$ saw [the person $]_{\mathrm{k}}$ [who dislikes himself $*_{\mathrm{i} / *_{\mathrm{j}} / \mathrm{k}}$ ].

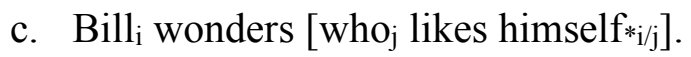

\footnotetext{
${ }^{8}$ In IRE, a reflexive can corefer with a possessor when the c-commanding nominal expression is inanimate, as illustrated below. These sentences were rated as having a mean naturalness rating of 2.58 , one of the highest in the study. Therefore, his in his behavior is an accessible antecedent.
}

(1) Hisi behavior harmed himselfi. 
These data indicate that the reflexive pronoun undergoes movement, which allows it to be in a local relationship with a nominal expression outside the simple finite clause. ${ }^{9}$

\subsection{IRE reflexives as true long-distance reflexives}

As illustrated above, IRE reflexive pronouns do not share the typical characteristics of long-distance reflexives in other languages: (i) they are bimorphemic, (ii) they can corefer with a subject or object, and (iii) IRE exhibits Blocking Effects despite having subject/verb agreement. It is possible that IRE reflexives are not true counterexamples to the generalized behavior of long-distance reflexives, but rather that they are members of one of the groups of apparent counterexamples mentioned in the introduction: (i) reflexive pronouns that have both anaphoric and pronominal characteristics or (ii) reflexive pronouns that have an anaphoric and a logophoric distribution. It is important to understand if IRE reflexive pronouns are true long-distance reflexives because this will help determine whether the generalized typological characteristics of long-distance reflexives are true. Understanding the classification of IRE reflexive pronouns will also help establish an appropriate analysis. If IRE reflexives have a logophoric distribution, then

\footnotetext{
${ }^{9}$ Most judgments about island effects were collected after the Magnitude Estimation task. This is because previous research suggested to me that IRE reflexive pronouns behaved like those bimorphemic reflexive pronouns that can corefer with a nominal expression outside their simple finite clause, such as Malay diri-nya 'himself/herself' or Japanese karezisin 'himself.' Therefore, I thought that IRE reflexive pronouns would either have (i) both an anaphoric and a pronominal distribution or (ii) both an anaphoric and a logophoric distribution. Neither of these distributions is expected to exhibit island effects. However, three stimuli with a reflexive pronoun in an island were included in the ME task. These stimuli were rated significantly worse than sentences where the reflexive pronoun was not in an island $(t(12)=-2.88, \mathrm{p}=.003)$. Three informants gave judgments for sentences with additional types of islands, and there was consensus that sentences in which a reflexive was in an island were not as natural as sentences in which the reflexive was not in an island.
} 
(at least) a partially discourse or pragmatic analysis is required, since the distribution of logophoric expressions are thought to be governed by discourse or pragmatic principles rather than solely syntactic principles (Kuno 1987, Sells, 1987, Zribi-Hertz 1989, Huang \& Liu 2001, Baker 1995, inter alia). On the other hand, if they do not have a logophoric distribution, then only a syntactic analysis is required. In the sub-sections below, I explore whether or not IRE reflexive pronouns are true or only apparent counterexamples of the generalized distribution of long-distance reflexives. I show that IRE reflexives are true counterexamples because they do not have a truly pronominal distribution nor do they have a truly logophoric distribution.

\subsubsection{IRE reflexive pronouns do not have a truly pronominal distribution}

Unlike Malay dirinya, IRE reflexive pronouns do not have both a pronominal and an anaphoric distribution. Pronominals do not exhibit Blocking Effects (as in (13)) or island effects (as in (14)):

(13) Hillaryi said that I believe in heri. (c.f. (5))

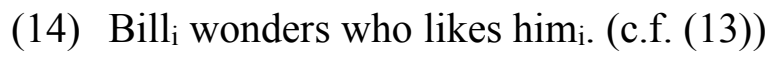

If IRE reflexives had the same distribution as pronominal elements, they would not exhibit Blocking Effects or island effects. However, IRE reflexives exhibit both effects. Thus, I conclude that IRE reflexives are not indeterminate between anaphors and pronominals.

\subsubsection{IRE reflexive pronouns do not have a truly logophoric distribution}

In this section, I show that IRE reflexive pronouns do not have a truly logophoric distribution. Nominal expressions that have a logophoric distribution typically occur in specific discourse or pragmatic environments that indicate: (i) the source of information, (ii) the mental state of a protagonist, or (iii) the point of view of the protagonist (Sells 1987). IRE reflexive pronouns that corefer with nominal expressions outside their simple finite clause can occur in 
sentences with verbs such as say (which indicates source of information), and also think and know (which indicate the mental state of the protagonist). If IRE reflexive pronouns were logophoric in nature, they should occur in (i) other environments where the source of information is apparent (but not in environments where the source is not the antecedent) and (ii) other environments in which the mental state of the protagonist is referred to (but not in environments where the mental state of the protagonist is not referred to). In fact, IRE reflexives can corefer with an antecedent that is, or is not, the source of information. Similarly, IRE reflexives can corefer with a nominal expression even when the protagonist's mental state is not referred to. Thus, IRE inconsistently exhibits "source" and "self" effects. I will illustrate this inconsistency below. Additional evidence that IRE reflexive pronouns are not truly logophoric in nature comes from Blocking Effects, as I will discuss below. Finally, the existence of island effects also suggests that IRE reflexives are not fully logophoric in nature since the distribution of logophoric expressions is governed by specific pragmatic/discourse environments, but island effects are a result of a specific syntactic environment.

This section is organized as follows. First, I provide an overview of logophoric expressions and their relationship with long-distance reflexives. Next, I illustrate that IRE reflexive pronouns inconsistently exhibit logophoric effects that we do not expect to be inconsistent. Then, I illustrate that Blocking Effects provide further evidence that IRE reflexive pronouns are not fully logophoric in nature. Lastly, I suggest that island effects provide further evidence that IRE reflexives are not truly logophoric in nature.

Logophoric pronouns occur in a specialized set of environments. Sells (1987: 462) proposes a pragmatic/discourse taxonomy that outlines the distribution of logophoric pronouns in 
"mixed logophoric languages." ${ }^{10} \mathrm{He}$ claims that "an unanalyzed notion of the 'speaker' or the 'I' [...] does not allow for enough distinctions to be drawn when a range of languages are considered." He claims that there is "no unified notion of logophoricity per se and that logophoric phenomena are instead a result of the interaction of these more primitive notions: the source of the report, the person with respect to whose consciousness (or 'self') the report is made, and the person from whose point of view the report is made." Sells goes on to define each of these logophoric roles (455):

a. The SOURCE is the one who makes the report (e.g., the speaker);

b. The SELF represents the one whose "mind" is being reported;

c. The PIVOT represents the one from whose point of view the report is made, the center of deixis

Sells suggests that languages differ as to whether they permit logophoricity in one, two or all three environments (SOURCE, SELF, and PIVOT). Other researchers, such as Huang and Liu (2001), suggest that these environments form a hierarchical order. They posit that SOURCE is the 'core' environment, SELF is the 'extended' environment, and PIVOT is the 'further extended' environment. Huang and Liu go on to say that they expect languages to exhibit logophoric pronouns in a SOURCE environment before exhibiting them in a SELF environment, and in SOURCE and SELF environments before exhibiting them in all three environments. Huang and Liu further claim that we would not expect to find a language that allows PIVOT environments but does not allow SOURCE environments.

${ }^{10}$ Languages where the reflexive pronoun and the logophoric expression take the same morphological form (as opposed to languages like Ewe where the reflexive pronoun and logophoric pronoun are morphologically distinct) are considered mixed logophoric languages (Culy 1994). 
The relationship between long-distance reflexives and logophoric expressions is not well understood. One claim is that long-distance reflexives may be logophoric expressions. Evidence for this claim comes from Scandinavian languages and Japanese. Much data from Scandinavian languages suggest that a reflexive pronoun (e.g., Icelandic sig) can corefer with a nominal expression outside its minimal clause only when it is in an environment with predicates of communication and mental experience. Below is an example of a reflexive pronoun behaving like a logophoric expression in Icelandic (Maling 1984:212):

(16) Jón segir að Maria elski sig.

John says that Maria lovesó REFL

'John says that Maria loves him.'

Here, sig 'self' corefers with the person whose words are being presented, Jón (the SOURCE), not the nominal expression in the same clause (Maria). The distribution of the Icelandic reflexive supports the view that this lexical item is a logophoric expression because it corefers with the person whose words are being presented instead of a nominal expression that is structurally local.

Another claim is that long-distance reflexives are really anaphoric expressions that can undergo a "logophoric conversion" to a pronominal (in the sense of Chomsky's (1986) Binding Theory) in logophoric environments. Evidence for this claim comes from the distribution of Mandarin Chinese long-distance reflexives (Liu 1999, Huang \& Liu 2001). In Mandarin, there is an asymmetry in Blocking Effects (Xu 1993, Pan 1997), and nominal expressions that cannot be antecedents (such as objects) can trigger Blocking Effects. These facts are explained below. ${ }^{11}$

\footnotetext{
${ }^{11}$ It should be noted that a recent study by He and Kaiser (2011) found that Blocking Effects in Mandarin are not consistent. In a forced choice test about the interpretation of a sentence, a first person local subject did not prevent the bare reflexive ziji from coreferring with a third person subject in the matrix clause. In fact, a higher than
} 
Mandarin exhibits an asymmetry in Blocking effects: a local first or second person nominal expression blocks a remote third person nominal expression from being an antecedent; however, a local third person nominal expression does not block a remote first or second person nominal expression from being an antecedent, as illustrated below (Huang \& Liu 2001: 147):

\section{Zhangsan ${ }_{\mathrm{i}}$ danxin $\mathrm{woj}_{\mathrm{j}} / \mathrm{ni}_{\mathrm{j}}$ hui piping $\mathrm{ziji} *_{\mathrm{ij}}$}

Zhangsan worry I/you will criticize self

'Zhangsan is worried that I/you might criticize myself/yourself/*him.'

(18) Woi danxin Zhangsanj hui piping ziji $\mathrm{W}_{\mathrm{i} j}$

I worry Zhangsan will criticize self

'I am worried that Zhangsan will criticize ?me/himself'

(19) $\mathrm{Ni}_{\mathrm{i}}$ danxin Zhangsan ${ }_{\mathrm{j}}$ hui piping $\mathrm{ziji}_{\mathrm{i} \text { j }} \mathrm{ma}$ ?

You worry Zhangsan will criticize self $Q$

'Are you worried that Zhangsan will criticize ?you/himself.

Liu (1999) and Huang and Liu (2001) claim that logophoric environments allow only one center POV (point of view). Switching the POV in a sentence is not allowed in a logophoric environment (c.f. Chen 2009). They claim that first person wo 'I' and second person $n i$ 'you' indicate a shift in

expected number of forced choice interpretations indicated that the bare reflexive could corefer with a third person matrix subject when there was a first person local subject $(26.88 \%$ answers that reported coreference with the matrix subject vs. $73.12 \%$ answers that reported coreference with the local subject). This is in contrast to a sentence where there should be no Blocking Effects: a sentence with a third person local and matrix subject $(14.33 \%$ answers that reported coreference with the matrix subject vs. $85.67 \%$ answers that reported coreference with the local subject). Mainland China Mandarin speakers participated in He and Kaiser's study while mostly Taiwanese Mandarin speakers participated in Huang's research. This difference in Blocking Effects may be due to regional differences. 
perspective while third person nominal expressions (such as Zhangsan) do not allow a shift in perspective. Since a shift of perspective is not allowed for logophors, sentences with a first or second person intervening nominal expression are ungrammatical. In contrast, sentences with an intervening third person expression do not create a shift in perspective so they are grammatical.

In Mandarin, nominal expressions that cannot be antecedents (such as objects) can nevertheless trigger Blocking Effects. Nominal expressions in object (or oblique object) position cannot act as antecedents (Cole et al 2006: 34, Pollard \& Xue: 296):

(20) a. Zhangsan ${ }_{i}$ cong Lisi $i_{j}$ chu tingshuo Wangwu $u_{k}$ bu xihuan ziji $i_{i} *_{j k}$

Zhangsan from Lisi place hear Wangwu not like self

'Zhangsan heard from Lisi that Wangwu does not like him/himself.'

b. Zhangsan ${ }_{i}$ song (gei) Lisij yi-zhang ziji ${ }^{*}{ }^{*}$-de xiangpian.

Zhangsan give to Lisi one-CL self's picture

'Zhangsan gives Lisi a picture of himself.'

In both (20)a and (20)b, ziji cannot corefer with Lisi, which is not in subject position. Interestingly, objects can trigger Blocking Effects even though they are not potential antecedents (Cole et al 2006: 59).

(21) Zhangsan ${ }_{i}$ cong $\mathrm{ni}_{\mathrm{j}}$ nar ting shuo Malik hen taoyan $\mathrm{ziji} \mathrm{i}_{\mathrm{i} / \mathrm{j}_{\mathrm{j}} \mathrm{k}}$

Zhangsan from you there hear say Mary very hate self

'Zhangsan heard from you that Mary hates herself.'

This distribution is posited to be due to ziji's ability to undergo a logophoric conversion. Liu and Huang (2001) and Liu (1999) suggest that it is expected that objects can trigger Blocking Effects because the object nominal expression can indicate a shift of Point Of View, much like the subject nominal expressions above. The sentence in (21) is especially interesting because the 
SOURCE of information is $n i$ 'you'; Zhangsan is not the source of information, which precludes him from being the antecedent of the logophoric expression. In fact, it is suggested that in Mandarin there are two conditions required for ziji to corefer with a nominal expression outside the minimal clause: it must be in a logophoric environment and the antecedent must c-command the reflexive pronoun (e.g., Cole et al 2006).

A final possibility is that long-distance reflexive pronouns do not necessarily have a relationship with logophoric expressions, as I suggest is the case for IRE reflexive pronouns. Below, I explore whether or not IRE reflexive pronouns behave like logophoric expressions and conclude that they do not. As mentioned above, IRE reflexive pronouns exhibit long-distance interpretations with SOURCE verbs (e.g., say) and SELF verbs (e.g., think, know):
a. Johni said that [Matt believes in himselfi $\mathrm{f}_{\mathrm{i}}$.
b. John $n_{\mathrm{i}}$ thinks that [Matt believes in himself $\mathrm{i}$.
c. John $n_{\mathrm{i}}$ knows that [Matt believes in himselfi]

Since IRE reflexive pronouns occur in the above SOURCE and SELF environments, it is expected that their distribution will be affected by other SOURCE and SELF environments if they are logophoric in nature. However, this is not the case. For example, IRE reflexive pronouns can corefer with non-SOURCE nominal expressions, as in (23) below. Here, the SOURCE of the information in this sentence is me. However, himself can corefer with the non-SOURCE subject of the matrix clause, John. Also note that, unlike in Mandarin, the first person object me does not trigger Blocking Effects:

(23) John $n_{i}$ heard from me that $\left[\right.$ Tom $_{j}$ likes himself $\left._{i j}\right]$.

Likewise, in sentences with told, the non-SOURCE nominal expression can be the antecedent of the reflexive, as illustrated below: 
$\mathrm{John}_{\mathrm{i}}$ told Bill $\mathrm{j}_{\mathrm{j}}$ that $\left[\right.$ Tomk $_{\mathrm{k}}$ likes himself $\left._{\mathrm{i} j \mathrm{k}}\right]$.

Here, himself can corefer with Bill, which is the receiver rather than the SOURCE of information. Thus, IRE reflexives do not exhibit SOURCE effects since they can corefer with both SOURCE and non-SOURCE antecedents.

Similarly, the distribution of IRE reflexive pronouns is not as expected in all SELF environments. IRE does not exhibit consciousness or because effects, which is a SELF environment. Iida and Sells (1988) claim that the use of because denotes that the external speaker is making a judgment about the causal relation between two events from the internal protagonist's point of view. In contrast, when makes no such judgment. Therefore, sentences with because should be rated differently than sentences with when. I did not find a difference in naturalness ratings for these two sentences in my data $(t(12)=.14, \mathrm{p}=.89)$ :

a. Craig ${ }_{\mathrm{i}}$ is happy when Matt $\mathrm{j}_{\mathrm{j}}$ believes in himself $\mathrm{f}_{\mathrm{ij}}$.

b. Craig is is happy because Matt $t_{j}$ believes in himself $\mathrm{f}_{\mathrm{i} j}$.

One would expect that logophoric expressions would consistently behave like logophoric expressions. In IRE, reflexive pronouns do not consistently have a logophoric distribution; there are inconsistent SOURCE and SELF effects in IRE. This is evidence that IRE reflexive pronouns do not have a truly logophoric distribution.

An additional piece of evidence that IRE reflexive pronouns are not truly logophoric in nature is that Blocking Effects in IRE do not pattern like Blocking Effects in languages in which the reflexive pronoun undergoes a logophoric conversion, like Mandarin Chinese. Recall that there is an asymmetry of Blocking Effects found in Mandarin. A local first or second person nominal expression blocks a remote third person nominal expression from being an antecedent; however, a local third person nominal expression does not block a remote first or second person nominal 
expression from being an antecedent. Huang and Liu (2001) suggest that ziji cannot undergo a conversion from an anaphor to a pronominal when there is an intervening first or second person nominal expression because the second or first person nominal expression changes the Point of View that is represented in the sentence. Since the Point of View is changed, the logophoric environment is lost. In contrast, they claim that an intervening third person nominal expression does not change the Point of View represented in the sentence. Therefore, when there is an intervening third person nominal expression, the logophoric environment is not lost, allowing the reflexive to corefer with a long-distance antecedent. I did not find such an asymmetry in the IRE data. Nominal expressions blocked long-distance interpretations regardless of the person feature (first, second, or third) on the intervening nominal expression. The sentences below were rated similarly $(t(12)=1.08, \mathrm{p}=.3)$ :

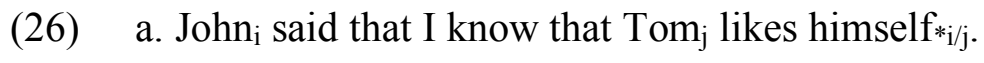

b. John $n_{\mathrm{i}}$ said that you know that Tom likes himself $*_{\mathrm{i} j \mathrm{j}}$.

c. ${ }^{*} \mathrm{I}_{\mathrm{i}}$ said that Bill believes in myself $\mathrm{f}_{\mathrm{i}}$.

d. * You $_{\mathrm{i}}$ said that Bill believes in yourself $\mathrm{i}_{\mathrm{i}}$

Recall that in Mandarin nominal expressions in object position can act as blockers, even though they cannot act as binders. This was taken as evidence that ziji has logophoric qualities.

In IRE, a nominal expression in object position does not trigger Blocking Effects, as illustrated below:

(27) $\mathrm{John}_{\mathrm{i}}$ told me that $\left[\mathrm{Tom}_{\mathrm{j}}\right.$ likes himself $\left.\mathrm{i}_{\mathrm{j}}\right]$. 
Here, me does not prevent himself from coreferring with the subject of the matrix clause John. Sentences like (27) were rated similarly to sentences with no mismatching nominal expression in object position $(t(12)=1.71, \mathrm{p}=.11) .{ }^{12}$

Lastly, if IRE reflexive pronouns were logophoric in nature, they would require a pragmatic/discourse analysis rather than a syntactic analysis. A pragmatic/discourse analysis would not be able to account for the island effects exhibited by the reflexives (illustrated above in (12) and repeated below), since island effects are a syntactic phenomenon rather than a discourse/pragmatic phenomenon.

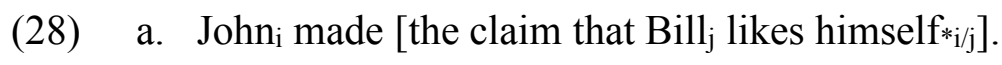

b. Bill $l_{\mathrm{i}}$ said that Paul $\mathrm{j}_{\mathrm{j}}$ saw [the person $]_{\mathrm{k}}\left[\right.$ who dislikes himself $\left.*_{*_{\mathrm{i}} / *_{\mathrm{j}} / \mathrm{k}}\right]$.

c. Bill $_{\mathrm{i}}$ wonders $\left[\right.$ who $_{\mathrm{j}}$ likes himself $\left.*_{\mathrm{i} / \mathrm{j}}\right]$.

The distribution of IRE reflexive pronouns illustrates that they are not truly logophoric in nature since they do not consistently show logophoric effects. Also, as we previously saw, IRE reflexive pronouns do not have a true pronominal distribution. Thus, IRE reflexive pronouns are true long-distance reflexives despite being bimorphemic.

\footnotetext{
${ }^{12}$ Sentences like (5) and (34) may look similar to sentences used to discuss logophoricity in British English (e.g. Zribi-Hertz (1989), Baker (1995), and Safir (1992)); and there may be a logophoric-like distribution of some reflexive pronouns in Iron Range English. I think what is important is the fact that the distribution of IRE reflexives is not fully logophoric. If IRE reflexives were fully logophoric in nature, as suggested for British English reflexives, we would get a different distribution. This research helps establish a line between the behavior of long-distance reflexives and logophoric expressions, but further research is needed to better distinguish behavioral characteristics between the two phenomena.
} 


\section{Analysis}

In this section I present an analysis that is reminiscent of previous analyses for longdistance reflexives in that (i) the reflexive pronoun undergoes covert movement to a position where it is in a local relationship with a nominal expression in a higher clause, and (ii) binding and Blocking are separate processes. Below, I employ the Agree operation to account for binding facts (cf. Hicks 2010) and the Multiple Agree operation to account for Blocking facts (cf. Hasegawa 2005). I assume a phase-based analysis using Chomsky's (2001) version of the Phase Impenetrability Condition:

(29) Phase Impenetrability Condition (PIC) (Chomsky 2001: 14)

[Given the structure $[\mathrm{zP} Z \ldots$. . [н $\alpha$ [H YP]]], with $\mathrm{H}$ and $\mathrm{Z}$ the heads of phases]: The domain of $\mathrm{H}$ is not accessible to operations at $\mathrm{ZP}$; only $\mathrm{H}$ and its edge are accessible to such operations.

\subsection{Evidence that IRE reflexive pronouns undergo raising}

Two pieces of evidence suggest that IRE reflexive pronouns undergo raising in order to be in a local relationship with a nominal expression in a higher clause: island effects and Blocking Effects. Recall that IRE reflexive pronouns in islands cannot corefer with nominal expressions outside their simple finite clause, as illustrated in (12), repeated below:

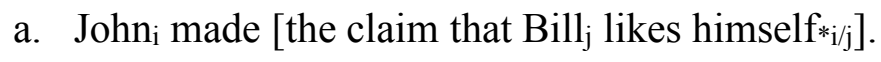

b. Bill $l_{\mathrm{i}}$ said that Paul $\mathrm{j}_{\mathrm{j}}$ saw $[\text { the person }]_{\mathrm{k}}\left[\right.$ who dislikes himself $\left.*_{\mathrm{*}_{\mathrm{i}} / *_{\mathrm{j}} / \mathrm{k}}\right]$.

c. Bill $\mathrm{i}_{\mathrm{i}}$ wonders $\left[\mathrm{who}_{\mathrm{j}}\right.$ likes himself $\left.*_{\mathrm{i} / \mathrm{j}}\right]$.

This suggests that the reflexive must raise in order to be in a local relationship with a nominal expression in a higher clause. Since the reflexive pronoun cannot raise out of an island to be in a local relationship with a nominal expression in the higher clause, it cannot corefer with a 
nominal expression outside its finite clause.

Blocking Effects also provide evidence that the IRE reflexive pronouns undergo raising since Blocking Effects suggest that the reflexive must move through (and be evaluated at) each clause in order for the reflexive to corefer with a nominal expression in a higher clause (Cole, Hermon \& Huang 2006). Since an intervening nominal expression in subject position that does not match the reflexive pronoun for person blocks the reflexive from coreferring with an expression in a higher clause, the reflexive must move through each phase and be evaluated at each phase. Examples of Blocking Effects in IRE are above in (6), repeated below:

a. Hillaryi said that [she believes in herself $f_{i}$.

b. Hillary ${ }_{i}$ said that [he believes in herself $f_{i}$.

c. *Hillaryi said that [I believe in herselfi].

d. *Hillaryi said that [you believe in herself $\mathrm{i}_{\text {] }}$.

I suggest that IRE reflexives have an operator-like quality that allows them to behave like wh-words in English. Like other operators, IRE reflexive pronouns move successive-cyclically to [Spec, CP] where they are local to potential antecedents in higher clauses. Similar analyses have been proposed for other long-distance reflexives (e.g., Japanese zibun "self" (Katada 1991), the Romance clitic se "self" (Zubizarreta 1987), and Mandarin ziji "self” (Huang \& Liu 2001)). In fact, Katada (1991) suggests that two types of reflexives exist cross-linguistically: operator and non-operator anaphors. Operator anaphors, which can undergo raising, can corefer with a longdistance antecedent while non-operator anaphors, which cannot undergo raising, must corefer with an antecedent within their same clause.

It has been suggested that operator anaphors lack information such as number, person, and gender. It has been posited that lacking $\varphi$-features contributes to the operator-status of the reflexive 
form (e.g. Cole, Hermon \& Huang 2003). However, an operator may be marked for $\varphi$-features. For example, the interrogative who in English is specified for the $\varphi$-feature number; who is singular, as the verb must have singular agreement morphology, illustrated below:

(32) Who is at the door?

(33) *Who are at the door?

Similarly, in Greek the interrogative who is an operator, despite being overtly marked for all $\varphi$ features: person, number, and gender. The declension of the Greek third person who is shown below (Katada 1991: 293):

\section{Declension of Greek who}

\begin{tabular}{|l|l|l|l|}
\hline & Masculine & Feminine & Neuter \\
\hline Singular & piós & piá & pió \\
\hline Plural & pií & piés & piá \\
\hline
\end{tabular}

Thus, operator-hood and the marking of $\varphi$-features are not mutually exclusive. The cross-linguistic distribution of who suggests that operator-hood is not dependent on the number of morphemes in a reflexive form or the specification of person, number and gender features on the reflexive form.

\subsection{Binding Process}

I posit that IRE reflexives have a [VAR] feature that must be assigned a value by a ccommanding nominal expression within the same phase via Agree (c.f. Hicks' (2010) analysis of (Standard) English anaphors). Rezac (2004) and Baker (2008) suggest that a probe can search upwards for a value when a typical downward probe does not produce a goal, as is the case for reflexive pronouns. In the current analysis, reflexives have an unvalued [VAR] (VARIABLE) feature since they do not have an inherent capacity for reference. The Agree operation accounts for coreference between the reflexive pronoun and its antecedent and provides an inherent c-command relationship between the two nominal expressions. Hicks (2009) proposes the following structure for Standard English reflexives with the unvalued [VAR] feature: 
Structure of Standard English reflexives (Hicks 2009: 127)

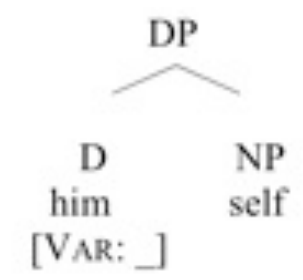

In Hicks' analysis, both the subject (John) and the object (Bill) of the most embedded simple finite clause in the sentence in (36) are available as potential antecedents. Both c-command the reflexive in the phase before the subject moves to [Spec, TP]. Note that Agree is "local" due to the Phase Impenetrability Condition above in (29).

Craigi knows that [TP John $\left[{ }_{v \mathrm{P}}<\mathrm{John}_{\mathrm{j}}>\right.$ gave Bill $_{\mathrm{k}}$ a book about himself $\left.*_{\mathrm{i} j \mathrm{j} k}\right]$

Importantly, Hicks' analysis allows for more than one interpretation when the reflexive is in a wh-phrase. Wh-phrases move to [Spec, $\mathrm{CP}]$ where they can participate in operations of higher phases. According to Hicks, the Agree operation is free to apply at any point in the derivation while $w h$-phrases undergo raising. An example sentence is in (37), and its derivation is in (38):

(38) $\left[\mathrm{CP}\right.$ John wondered $\left[{ }_{\mathrm{CP}}<\right.$ which pictures of himself $>$ Bill claimed $[\mathrm{CP}<$ which pictures of himself $>$ Paul had bought $<$ which pictures of himself $>$ ]]] [VAR] can be valued at any point in the derivation: it can be valued before the operator phrase raises (valued by Paul), it can be valued after it moves to the [Spec, CP] of the minimal clause (valued by Bill), or it can be valued after it moves to the $[\mathrm{Spec}, \mathrm{CP}]$ of the middle clause (valued by John). Once valued, the [VAR] feature on the reflexive keeps its value throughout the derivation.

Recall that island effects and Blocking Effects suggest that IRE reflexives undergo raising in order to have a long-distance interpretation. In order to participate in processes of higher clauses, IRE reflexives must be at the edge of the phase: the [Spec, $\mathrm{CP}]$ position. Below is the proposed 
structure of IRE reflexives, with both an unvalued [VAR] feature (similar to Standard English reflexives) and an operator-like [OP*] feature (dissimilar to Standard English reflexives):

$$
\text { Proposed structure of Iron Range English reflexives }
$$

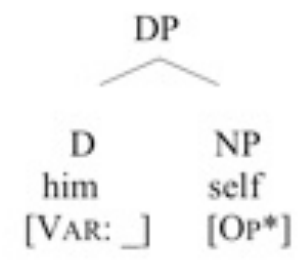

The main difference between Iron Range English reflexives and Standard English reflexives is that Iron Range English reflexives have an inherent operator-like quality that Standard English reflexives lack. The operator feature allows the Iron Range English reflexive to raise to a position where it can participate in operations of higher phases. Since the Standard English reflexive lacks an operator feature, it must corefer only with a nominal expression within its same phase. Thus, in an Iron Range English sentence like (40), himself can corefer with Mike, Bill, or John because himself raises to the [Spec, $\mathrm{CP}]$ of each higher clause. The derivation is below in (41):

(41) $\left[\right.$ cP himself John said that $\left[{ }_{\mathrm{CP}}<\right.$ himself $>$ Bill knows that $\left[{ }_{\mathrm{CP}}<\right.$ himself $>$ Mike likes $<$ himself $>$ ]]

The [VAR] feature may be valued in the simple clause (Mike), middle clause (Bill), or matrix clause $(J o h n)$. Note that if himself raises to the [Spec, CP] of the matrix clause without being valued, the derivation will crash. The Agree operation accounts for long-distance ability of the reflexive and why both subjects and objects are possible antecedents. This operation does not explain Blocking Effects because only subjects trigger blocking effects, and the binding process accounts for both subjects and objects being available as potential binders. 
Below is a derivation that illustrates that both subjects and objects (i) can be in the same phase and (ii) can c-command the reflexive within that phase. Both subjects and objects are within the same phase $(v \mathrm{P})$ and both c-command the reflexive (in its upward probe area) below in 0 . Therefore, the $[\mathrm{VAR}]$ feature on the reflexive pronoun can be valued from either the object or the subject within its same phase if the reflexive has not raised yet to [Spec, CP]. Alternatively, the [VAR] feature on the reflexive can be valued by the subject or object in the immediately higher $(v \mathrm{P})$ phase if the reflexive has raised to $[\mathrm{Spec}, \mathrm{CP}]$ - via $[\mathrm{Spec}, v \mathrm{P}]$ - which is the edge of the phase. (42) Bill told John that Tom believes in himself.

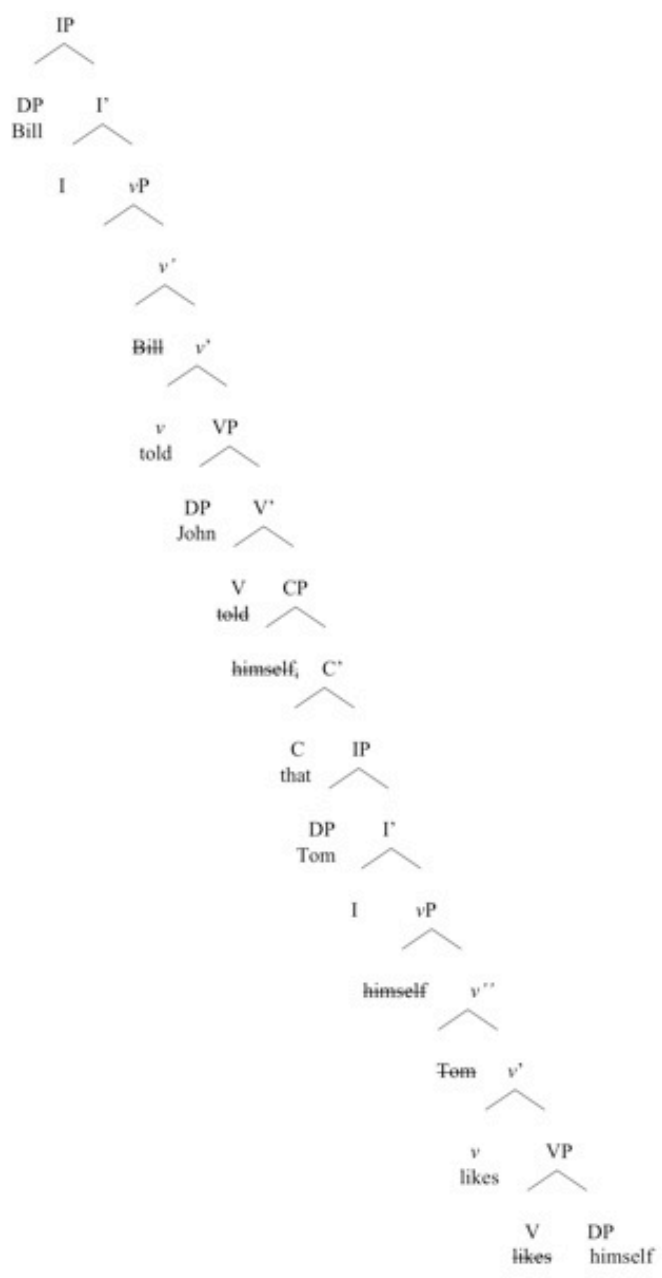


The [VAR] feature on himself can be valued by Tom in the simple finite clause, or by either John in object position or Bill in subject position after the reflexive pronoun has undergone raising to the lowest [Spec, CP].

\subsection{Blocking Process}

Recall that only subjects that do not agree with the reflexive for person trigger Blocking Effects. Objects and possessors do not. Thus, an additional mechanism that requires that the reflexive and the subject agree for person features is necessary to account for the Blocking Effects in IRE. Hasegawa (2005) and Kratzer (2009) both propose operations that, with minor adjustments, would account for Blocking Effects in Iron Range English, though their proposals are originally meant to account for binding facts. Hasegawa's (2005) and Kratzer's (2009) proposals are similar in that they both suggest a functional head licenses the reflexive. Each linguist also proposes a type of Agree operation to ensure that $\varphi$-features match between the subject and the reflexive. Hasegawa proposes that the reflexive is licensed by $\mathrm{T}$, and that a Multiple Agree operation (sensu Hiraiwa 2001) ensures that the subject, T, and the reflexive share $\varphi$-features. In contrast, Kratzer (2009) proposes that $v$ licenses the reflexive. She further proposes two separate operations to ensure that the subject and the reflexive match for $\varphi$ features. First, the subject DP unifies its $\varphi$-features with $v$. Then, $v$ and the reflexive undergo an Agree operation so that the reflexive is valued for $\varphi$-features. Both proposals are local, though Hasegawa adopts the weak version of Chomsky's (2001) Phase Impenetrability Condition while Kratzer adopts the strong version (Chomsky 2000). Both proposals use independently motivated mechanisms. More research must be done in order to understand if $v$ or $\mathrm{T}$ licenses reflexives, whether one Multiple Agree operation or two separate operations is preferable, and whether or not both the weak and the strong version of Chomsky's Phase Impenetrability Condition are 
necessary. Recall that both Hasegawa and Kratzer propose these operations to account for Binding facts, but I am using these operations to account for Blocking Effects. I will assume Hiraiwa's Multiple Agree operation (as presented in Hasegawa's binding analysis), and present my analysis for IRE reflexives with this operation even though Kratzer's analysis would also account for Blocking Effects in IRE with some minor adjustments.

Hasegawa uses Hiraiwa's (2001: 69-70) definition of Multiple Agree (formalized below in (43)). In this operation, a probe agrees with all the matched goals at the same derivational point in a single simultaneous operation if the goals are in a c-commanding relationship (represented by $>$ ) with the probe and each other:

MULTIPLE AGREE as a single simultaneous operation

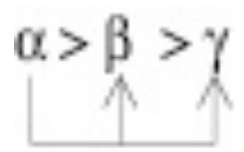

(Agree $(\alpha, \beta, \gamma)$ where $\alpha$ is a probe and both $\beta$ and $\gamma$ are matching goals for $\alpha$ ).

Note that while the domain of $v$ is not accessible to operations at $\mathrm{CP}$, it is accessible to operations "within" $\mathrm{CP}$. Thus, a head like $\mathrm{T}$ can establish an agreement relationship with $v \mathrm{P}$ internal dependents, given the PIC in (14) and a structure like that in (44):

$$
\text { [CP [TP T [vP [vp ]]]] }
$$

It is generally assumed in English that T undergoes agreement with the subject since English exhibits subject/verb agreement. Additionally, I propose that a T with a $[+$ multi] feature undergoes agreement with the reflexive since it has a unique relationship with the reflexive as the reflexive's licenser (it is a matched goal). In English, however, non-reflexives objects are not available goals: they are not generally in agreement with $T$, nor are they licensed by a $T$ with a [+multi] feature. This operation is advantageous because it targets only subjects; objects and possessors need not agree for person with the reflexive regardless of where the appear in the 
derivation.

There are two adjustments that I must make to Hasegawa's analysis in order to transfer it to Blocking Effects in Iron Range English. First, Hasegawa proposes that the $[+$ multi] feature on T requires that all $\varphi$-features between the subject and the reflexive agree. I suggest that only the person feature need agree between the subject and the reflexive. The idea that person is the important feature when considering binding data in English has also been suggested by Hicks (2009) and Heim (1998). Second, whereas Hasegawa (2005) proposes that reflexives need to be licensed by a [+multi] feature on T, I suggest that an unvalued [VAR] feature needs to be licensed by a $[+$ multi $]$ feature on $\mathrm{T}$.

Let us see how Multiple Agree accounts for Blocking Effects in IRE. Take (45) for example:

* $\mathrm{John}_{\mathrm{i}}$ knows that I said that Bill likes himselfi.

Here, Bill does not value the [VAR] feature on himself. Thus, the T of the embedded clause must have a $[+$ multi] feature in order to license the unvalued [VAR] feature on the reflexive. The $[+$ multi] feature requires that Bill and himself agree for person. Since they are both third person, the derivation continues. Next, himself raises to $[\mathrm{Spec}, \mathrm{CP}]$ where it can participate in operations of higher phases, such as value its [VAR] feature from a higher nominal expression. $I$ does not value the [VAR] feature on himself. Again, in order to license the unvalued [VAR] feature on the reflexive, a $\mathrm{T}$ with a $[+$ multi] feature is merged to the structure. The $[+$ multi $]$ feature requires that $I$ and himself agree for person. This time, there is a mismatch for person, as $I$ is first person and himself is third person. This causes the derivation to crash before himself raises to a position where it can have its [VAR] feature valued by John. 
Crucially, since the [+multi] feature on T licenses an unvalued [VAR] feature rather than licensing all reflexives, sentence like (46) and (47), which are well formed in Iron Range English, are allowed in the grammar:

(46) He told me $_{\mathrm{i}}$ about myself $\mathrm{f}_{\mathrm{i}}$

(47) I said that Tomi likes himselfi.

In (46), the [VAR] feature on myself is valued by me in the $v \mathrm{P}$ phase. Therefore, the $\mathrm{T}$ that merges to this structure will not have a [+multi] feature, since this feature is only needed to license an unvalued [VAR] feature on the reflexive. Thus, he and myself do not need to agree for person. Similarly, in (47) the [VAR] feature on himself is valued by Tom in the $v \mathrm{P}$ (before Tom raises out of the $v \mathrm{P})$. After the [VAR] feature is valued, higher Ts are merged without a $[+$ multi] feature. Therefore, I and himself are not required to agree for person.

Interestingly, this analysis suggests that the features associated with the $\mathrm{T}$ are similar between standard varieties of English and Iron Range English. Recall that in standard varieties of English there is no operator-like feature on the reflexive that allows it to participate in operations of higher clauses. Thus, the [VAR] feature of the reflexive must be valued within the $v \mathrm{P}$ (where both a c-commanding subject and a c-commanding object can value the [VAR] feature according to Hicks (2009)), or the derivation crashes. Due to this requirement, there will never be a situation where T merges to a structure that has an unvalued [VAR] feature on the reflexive; the derivation would not get that far. Since a $\mathrm{T}$ in Standard English never needs to license a reflexive with an unvalued [VAR] feature from a lower clause, the $\mathrm{T}$ will never be required to have a [+multi] feature. Therefore, the (possibly singular) difference between Iron Range English and Standard English reflexives that results in such different distributions is that Iron Range English reflexives have an operator-like feature that reflexives in Standard English lack. 
The following is a summary of the derivation of binding relationships in IRE. First, I claimed that IRE reflexives behave like operators in that they move successive-cyclically to [Spec, CP]. The evidence I used for this claim is: (i) the ability of the reflexive to participate in processes of higher phases, (ii) island effects, and (iii) Blocking Effects. The operator-like behavior of the reflexive allows it to corefer with nominal expressions outside its simple clause. Hicks' (2009) analysis, in which the unvalued [VAR] feature on the pronominal component of the reflexive agrees with a valued feature on another nominal expression in the phase, accounts for the local and long-distance uses of IRE reflexives. However, we noted that a reflexive is "blocked" from coreferring with a higher nominal expression if an intervening subject does not match the reflexive for person. A mismatch in number or gender, though, does not block the reflexive from coreferring with a higher nominal expression. Blocking Effects are not accounted for in Hicks' analysis. I suggested that a [+multi] feature on T both licenses an unvalued [VAR] feature on a reflexive and allows T to undergo Multiple Agreement for person with the subject and the reflexive, similar to Hasegawa (2005). If there is a mismatch between person features of a subject and a reflexive with an unvalued [VAR] feature, the derivation will crash. A T with a [+multi] feature undergoes Multiple Agree before each successive-cyclic raising of an IRE reflexive with an unvalued [VAR] feature. I maintain that Multiple Agree by T with the subject and reflexive pronoun does not constitute a binding relationship (contra Hasegawa 2005). Rather, the [+ multi] feature merely licenses an unvalued [VAR] feature on the reflexive. This analysis accounts for Blocking Effects. The reflexive must get its reference via the unvalued [VAR] feature with which it is generated (Hicks 2009).

This analysis accounts for the following facts: (i) that an IRE reflexive pronoun can corefer with a nominal expression outside its simple finite clause, (ii) that both subjects and objects can 
act as antecedents, (iii) that only a mismatch for person between a nominal expression in subject position and a reflexive with an unvalued [VAR] feature causes the derivation to $\mathrm{crash} .{ }^{13}$ First, IRE reflexives can corefer with a nominal expression outside their simple clause because they are operator-like, and, therefore, raise to a position in the sentence structure where they are able to participate in a binding relationship with nominal expressions in higher phases. Also, this analysis predicts that either the subject or the object of a sentence can act as an antecedent: both nominal expressions are in the same phase as the reflexive (within its simple clause or in a higher clause once the reflexive has moved), and each expression is valued for the [VAR] feature. Including an operation that ensures the feature person match between a subject nominal expression and a reflexive with an unvalued [VAR] features accounts for the facts that (i) only a mismatch in person feature will cause the derivation to crash and (ii) only subjects trigger Blocking Effects. If person is the only feature the [+multi] feature on T probes for, this is the only feature that must match between a subject and a reflexive with an unvalued [VAR] feature. Finally, Hasegawa suggested that the Multiple Agreement between the probe $\mathrm{T}$ and its goals, the subject and the reflexive, is a binding operation: Multiple Agree binds the reflexive to the subject. Note that using Hasegawa's analysis to account for the behavior of IRE reflexives does not work, since his analysis would predict only subject orientation. An IRE reflexive can have subject or object orientation.

\footnotetext{
${ }^{13}$ The role of $\mathrm{T}$ with subject agreement could possibly also be responsible for a preference for subject orientation of the reflexive over the object. However, more research needs to be done to establish if there is truly a preference for this. Schmelzer (2006) found that subject orientation was preferred over object orientation, but the current study does not find a preference for subject orientation over object orientation.
} 


\section{Conclusion and Directions for Future Research}

IRE reflexive pronouns are true long-distance reflexives despite (i) being bimorphemic, (ii) having both subject and object orientation, and (iii) exhibiting Blocking Effects along side subject/verb agreement. IRE reflexive pronouns are not underspecified for anaphoric and pronominal distribution, as posited for Malay dirinya 'himself/herself' because they do not have a true pronominal distribution. Similarly, IRE reflexive pronouns do not have logophoric qualities because they do not have a true logophoric distribution.

Though IRE reflexives appear to be very different from long-distance reflexives in other languages, their distribution supports main components of previous analyses for long-distance reflexives. Like monomorphemic reflexive pronouns, IRE reflexive pronouns undergo raising at LF to a position where they are in a local relationship with nominal expressions in higher clauses. Also, there is evidence from IRE that binding and Blocking are separate operations, since the two processes involve different sets of nominal expressions. Both subjects and objects are available as binders. In contrast, only subjects act as blockers.

One outcome of this research is the new knowledge that long-distance reflexives are not necessarily monomorphemic. Up until now, the number of morphemes has been a useful (if somewhat ad hoc) way to differentiate between local and long-distance reflexives in a variety of languages. For example, the Mandarin bimorphemic reflexive $t a-z i j i$ 'himself/herself' is a local reflexive while its monomorphemic counterpart ziji 'self' is a long-distance reflexive. Since the number of morphemes is no longer an accurate way to differentiate between these two types of reflexives, is there a more accurate way to distinguish between local and long-distance reflexives across and within languages? Possibly the difference between local and long-distance reflexives is 
that one is "intensified" while the other is not. Kaiser et al (2004) and similar work suggest that intensification, which they consider to be the addition of a morpheme, leads to a local interpretation of the reflexive while the lack of intensification (that is, the lack of an additional morpheme) leads to the possibility of a long-distance interpretation. I would like to take the idea of intensification a step further and suggest that intensification can be in the form of not only an additional morpheme (as in Mandarin), but also in the form of added phonological stress. My intuition as a speaker of IRE (which is shared by other speakers of IRE that I have consulted) is that reflexive pronouns produced with added stress must have a local interpretation, but reflexive pronouns produced without added stress on the first syllable may have a long-distance interpretation. Crosslinguistically, it may be that intensification of the reflexive, in the form of an added morpheme or added phonological stress, results in a local interpretation while the lack of intensification (that is, no added morpheme or no added phonological stress) results in the possibility of a long-distance interpretation. Further investigation of the intuition that stress on a reflexive leads to a local interpretation in IRE is the next step for research on this phenomenon.

\section{References}

Allen, H. 1976. The linguistic atlas of the upper Midwest, vol. 3. Minneapolis, MN: University of Minnesota Press.

Aronoff, Mark. 1976. Word Formation in Generative Grammar. Linguistic Inquiry Monograph No. 1. Cambridge: MIT Press.

Baker, C. 1995. Contrast, discourse prominence, and intensification, with special reference to locally free reflexives in British English. Language, 71(1), 63-101.

Bard, E. G., Robertson, D., \& Sorace, A. (1996). Magnitude Estimation of Linguistic Acceptability. Language, 72(1), 32-68. 
Baylis, A. 2007. Perceptions of audible nasal air emission in speakers with cleft palate: a comparative study of listener judgments, PhD Dissertation. University of Minnesota.

Bauer, M. 2005. Prosodic strengthening of consonants in Iron Range English. Dissertation. Georgetown University, Washington DC.

Chen, H. (2009). Logophoricity and ziji. Proceedings of the 21st North American Conference on Chinese Linguistics (NACCL-21), 2 (Edited by Yun Xiao. Smithfield, Rhode Island: Bryant University.), 464-481.

Chierchia, G. 1989. Anaphora and attitudes de se. In R. Bartsch, J. van Benthem and P. van Emde Boas, eds. Semantics and Contextual Expression: 1-31. Dordrecht: Foris.

Chomsky, N. 1981. Lectures on Government and Binding. Dordrecht: Foris.

Chomsky, N. 1986. Knowledge of Language: its nature, origin, and use. New York: Praeger Publishers.

Clements, G. N. 1975. The logophoric pronoun in Ewe: Its role in discourse. Journal of West African Linguistics 10:141 - 177.

Cole, P. \& G. Hermon. 2005. The typology of Malay reflexives. Lingua: 115, 627-644.

Cole, P., Hermon, G., \& Huang, C. J. 2003. Long-distance Reflexives: the State of the Art. In Syntax \& Semantics: Long Distance Reflexives, Ed. By Cole, Peter, Gabriella Hermon and C.-T. James Huang (Vol. 33). Elsevier Science and Technology Books.

Cole, P., Hermon, G. and Huang, C.T. James. 2006. "Long-Distance Anaphors: An Asian Perspective," Syncom Case 62b, Blackwell.

Cole, P., Hermon, G., \& Sung, L. 1990. Principles and parameters of long distance reflexives. Linguistic Inquiry, 21, 1-22. 
Cole, P., Sung, L.-M., 1994. Head movement and long distance reflexives. Linguistic Inquiry 25: 355-406.

Cole, P., \& Wang, C. 1996. Antecedents and blockers of long distance reflexives: the case of Chinese Ziji. Linguistic Inquiry, 27(3).

Cowart, W. 1997. Experimental Syntax: Applying Objective Methods to Sentence Judgments. Thousand Oaks, CA: Sage Publications.

Engen, T. 1971. Psychophysics II. Scaling methods. In Kling, J.W. and Riggs, L.A. (eds), "Woodworth and Schlosberg's Experimental Psychology." Holt, Rinehart and Winston, New York: 47-86.

Hagège, C. 1974. Les pronoms logophoriques. Bulletin de la Societe de Linguistique de Paris 69:287-310.

Harbert, W. 1995. 'Binding Theory, Control, and pro,' in G. Webelhuth (ed), Government and Binding Theory and the Minimalist Program, Basil Blackwell, Oxford, pp. 177-240. Hasegawa, H. (2005). Reflexive binding as Agreement and its interactions with the Phase System. In the world of Linguistic Research: A Festschrift for Kinsuke Hasegawa on the Occasion of His Seventieth Birthday, ed. Noriko Imanishi et al., (pp. 53- 69). Tokyo, Japan.

He, X. \& E. Kaiser. (2011). What 'I' Can Tell You about the Chinese Reflexive Ziji. Poster presented at the 85th Annual LSA Meeting. Pittsburgh, PA, January 6-9, 2011.

Hicks, G. 2009. The derivation of anaphoric relations. Amsterdam: John Benjamins Publishing Company.

Heim, Irene. 1998. Anaphora and semantic interpretation: a reinterpretation of Reinhart's approach. MIT Working Papers in Linguistics 25, 205-246. 
Hiraiwa, K. 2001. Multiple agree and the defective intervention constraint in Japanese. MIT Working Papers in Linguistics, 40, 67-80.

Huang, C. J., \& Liu, C. L. 2001. Logophoricity, attitudes and ziji at the interface. Syntax and Semantics, (33), 141- 196.

Iida, M. 1996. Context and Binding in Japanese. Stanford: CSLI.

Kaiser, E., J. Runner, R.S. Sussman, and M.K. Tanenhaus. 2004. Susceptibility to discourse/semantic factors: An experimental approach to short-distance pronouns and logophoric reflexives. Handout for Workshop on Semantic Approaches to Binding Theory, August 16th - 20th, ESSLLI'04 - Nancy, France.

Katada, F. 1991. The LF Representation of Anaphors. Linguistic Inquiry, 22(2), 287-313.

Kratzer, A. 2009. Making a Pronoun: Fake Indexicals as Windows into the Properties of Pronouns. Linguistic Inquiry, 40(2), 187-237.

Kuno, S. 1987. Functional Syntax, Chicago: University of Chicago Press.

Lee, Gunsoo. 2001. A minimalist account of long-distance anaphor Kucasin. Studies in Generative Grammar 11:2, 383-404.

Linn, M. 1988. The Origin and Development of the Iron Range Dialect in Northern Minnesota. Studia Posnaniensia, 21, 75-87.

Liu, C-S L. 1999. Anaphora in Mandarin Chinese and Binding at the Interface, PhD Dissertation. University of California, Irvine.

Maling, J. 1984. Non-clause-bounded reflexives in Modern Icelandic. Linguistics and Philosophy, 7(3), 211-241.

Pan, H. 1997. Constraints on Reflexivization in Mandarin Chinese. Garland Publishing, Inc., New York. 
Pica, P. 1987. On the nature of the reflexivization cycle. In proceedings of NELS 17 (vol. 2).

GLSA, University of Massachusetts: Amherst. 483-499.

Pollard C. and P. Xue. 1998. Chinese Reflexive Ziji: Syntactic Reflexives vs. Nonsyntactic Reflexives. Journal of East Asian Linguistics, 7(4), 287-318.

Rappaport, G. C. 1986. On anaphoric binding in Russian. Natural Language \& Linguistic Theory 4(1): 97-120.

Reuland, E. 2011. Anaphora and Language Design. Cambridge, MA: MIT press.

Safir, K. 1992. Implied Non-coreference and the Pattern of Anaphora. Linguistics and Philosophy 15, 1-52.

Schmelzer, S. 2006. "Long-distance anaphora: comparing Mandarin Chinese with Iron Range English. In LSO Working Papers Vol. 4, Blake Rodgers, ed. 118-130.

Sells, P. 1987. Aspects of Logophoricity. Linguistic Inquiry. 18.3.

Sirjamaki, J. 1965. The People of the Mesabi Range. In Selection from "Minnesota History": A Fiftieth Anniversary Anthology Minnesota: Minnesota Historical Society. 261-271.

Thráinsson, H. 1991. Long-distance reflexives and the typology of NPs. In Longdistance anaphora, ed. J. Koster and E. Reuland, 49 - 76. Cambridge: Cambridge University Press.

Underwood, G. 1981. The Dialect of the Mesabi Iron Range (Vol. 67). PADS.

Xu, L. 1993. The Long-Distance Binding of Ziji. Journal of Chinese Linguistics 21: 123141.

Zubizarreta, M. L.1987. Levels of Representation in the Lexicon and in the Syntax, Foris, Dordrecht. 
Zribi-Hertz, A. 1989. Anaphor Binding and Narrative Point of View: English Reflexive Pronouns in Sentences and Discourse. Language 65: 695-727. 